\title{
Retroflexion-induced perforation during colonos- copy after polypectomy: a word of caution
}
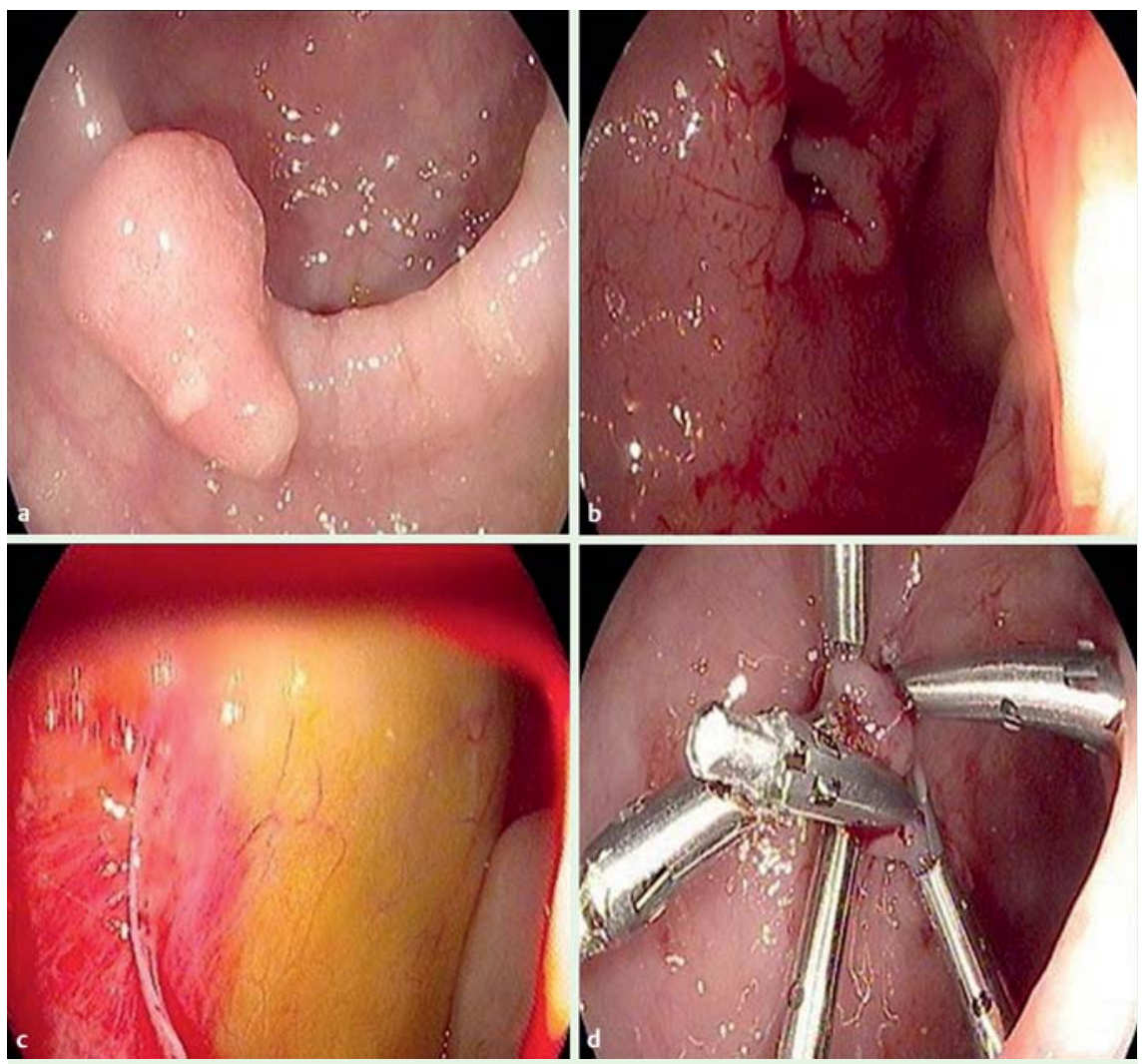

Fig. 1 Endoscopic views showing: a a small pedunculated rectal polyp; b a 4-cm linear perforation in the rectal wall that was apparent on straightening the scope after a retroversion maneuver had been attempted; $\mathbf{c}$ the intraperitoneal structures visible through the perforation in the rectal wall; $\mathbf{d}$ complete closure of rectal wall perforation with metal clips.

A 75-year-old man underwent colonoscopy (Pentax colonoscope, EC3970Li, air insufflation; Tokyo, Japan) for colorectal cancer screening and was found to have a small pedunculated polyp $(1 \mathrm{~cm})$ in the rectum ( $\bullet$ Fig. 1 a). A snare polypectomy was performed and the procedure was uncomplicated.

After the polypectomy had been completed, a retroversion maneuver was attempted. When the scope was straightened, a perforation measuring about $4 \mathrm{~cm}$ was noted in the rectal wall at the site of the polypectomy ( $\bullet$ Fig. $\mathbf{1} \mathbf{b}$ ), through which the intraperitoneal structures could be seen $(\boldsymbol{O}$ Fig. $1 \mathrm{c}$ ). Because the bowel had been well prepared and the perforation had been identified immediately, it was decided to manage the perforation with metal clips. We therefore placed six metal clips (Resolution M00522610; Boston Scientific, Natick, Massachusetts, USA) and completely closed the perforation ( $\bullet$ Fig. 1 d).
The patient received intravenous ceftriaxone (2 $\mathrm{g}$ once daily) and metronidazole (500 mg 8-hourly) for 5 days. A computed tomography (CT) scan of abdomen was done 48 hours later and showed no evidence of perforation or leakage of contrast from the rectum. He was discharged on the third day after the colonoscopy and was asymptomatic at follow-up. Histology showed the polyp to be a tubular adenoma.

Colonoscopy-related perforations are generally small $(<1 \mathrm{~cm})$ and if they are detected early, they can be managed with the application of metal clips. There are four reports of the closure of large perforations $(>3 \mathrm{~cm})$ with multiple clips [1-3] and with over-the-scope clips (OTSCs), which are used for closure of perforations of up to $2 \mathrm{~cm}$ but have also been used for larger perforations, though with somewhat lower overall success rates ( $88 \%$ for perforations $<3 \mathrm{~cm}$ and $75 \%$ for those $>3 \mathrm{~cm}$ ) [4]. However, the application of OTSCs to chronic lesions with surrounding fibrosis works less efficiently.

Rectal perforations related to colonoscopic retroflexion are usually small and below the level of the peritoneal reflection. The linear rent in this case indicates that the perforation was likely due to the scope tip and not to the bent section of scope [5].

We report a rare occurrence of a large retroflexion-related intraperitoneal rectal perforation that was closed successfully with metal clips. With this report, we reemphasize that after any therapeutic procedure in the rectum, retroflexion should be done with great caution, as even in expert hands, it can result in complications.

Endoscopy_UCTN_Code_CPL_1AJ_2AC

\section{Competing interests: None}

Anil K. John, Saad Al Kaabi, Ragesh B. Thandassery, Nazeeh Dweik

Department of Gastroenterology, Hamad General Hospital, Doha, Qatar

\section{References}

1 Trecca A, Gaj F, Gagliardi G. Our experience with endoscopic repair of large colonoscopic perforations and review of the literature. Tech Coloproctol 2008; 12: 315-322

2 Barbagallo F, Castello G, Latteri S et al. Successful endoscopic repair of an unusual colonic perforation following polypectomy using an endoclip device. World J Gastroenterol 2007; 13: 2889-2891

3 Velchuru VR, Zawadzki M, Levin AL et al. Endoclip closure of a large colonic perforation following colonoscopic leiomyoma excision. JSLS 2013; 17: 152 - 155

4 Nishiyama $\mathrm{N}$, Mori $\mathrm{H}$, Kobara $\mathrm{H}$ et al. Efficacy and safety of over-the-scope clip: including complications after endoscopic submucosal dissection. World J Gastroenterol 2013; 19 : 2752-2760

5 Ahlawat SK, Charabaty A, Benjamin S. Rectal perforation caused by retroflexion maneuver during colonoscopy: closure with endoscopic clips. Gastrointest Endosc 2008; 67: $771-773$

\section{Bibliography}

DOI http://dx.doi.org/

10.1055/s-0034-1365387

Endoscopy 2015; 47: E186

(c) Georg Thieme Verlag KG

Stuttgart · New York

ISSN 0013-726X

\section{Corresponding author}

Ragesh Babu Thandassery, MD

Department of Gastroenterology

Hamad General Hospital

Doha, Qatar

doc.ragesh@gmail.com 